\title{
The statistical logic of suicide terrorism
}

\author{
Simon Varaine* \\ Université Grenoble Alpes, CNRS, Science Po Grenoble, PACTE, 38000 Grenoble, France
}

\begin{abstract}
The self-sacrifice of suicide terrorists is subject to sophisticated models of altruistic sacrifice. Yet, a simpler account is that it reflects common suicidal tendencies. This paper offers new micro and macro evidence supportive of this hypothesis. Study 1 compared a sample of suicide and non-suicide terrorists in the United States from 1948 to 2017. Results indicated that suicide terrorists were more likely to display various established suicidal risk factors including history of child abuse, absent parent/s and relationship troubles. Study 2 took advantage of the cross-national variations in suicidal tendencies to explain the incidence of suicide and non-suicide terrorist attacks worldwide from 1991 to 2014. Results revealed that countries with higher share of deaths from suicide displayed higher incidences of suicide attacks but similar incidences of nonsuicide attacks. The decision of some terrorists to sacrifice their life may well have been subject to over-theorization.

Keywords: suicide terrorism, suicidal tendencies, terrorism, altruism, self-sacrifice
\end{abstract}

\footnotetext{
* Corresponding author

Email address: simon.varaine@etu-iepg.fr (Simon Varaine)
} 
"The most dangerous creation of any society is the man who has nothing to lose"

James Baldwin

\section{Introduction}

Suicide terrorists are individuals who purposely sacrifice their life in perpe5 trating violence for political aims (Pape, 2006, Atran, 2003). The self-sacrifice of suicide terrorists seems challenging for standard theories of human behavior. From a rational perspective, suicide terrorists deliberately act against their interest in self-preservation. From an evolutionary perspective, suicide terrorists avoid any future opportunity for personal reproduction on the behalf of non-kin relatives, which seems hardly compatible with natural selection.

The foremost explanation considers that suicide terrorism is an extreme form of altruistic devotion to the group Atran, 2016, Ginges \& Atran, 2009, Swann et al., 2012, Sheikh et al., 2016; Whitehouse, 2018; Ginges et al. 2009, Whitehouse et al. 2017, Pape, 2006). Extreme altruism would have evolved through a multilevel selection process, allowing groups with altruistic individuals to survive and other to disappear (Whitehouse, 2018, Whitehouse et al., 2017, Atran, 2016, Atran \& Sheikh, 2015). Yet, this hypothesis encompasses problems in evolutionary theory. Multilevel selection only occurs under specific conditions and should be considered the exception (Maynard Smith, 1976, Dawkins, 2016). Simulation studies do find that multilevel selection may foster altruism in specific conditions (Choi \& Bowles, 2007, Bowles, 2009, García \& van den Bergh, 2011; Whitehouse et al. 2017), but they rest on the assumption that altruistic individuals have a non-null probability to survive and transmit their genes. In sum, multilevel selection may explain why individuals risk their lives for the group; there is however a qualitative step in explaining why individuals knowingly sacrifice their life for the group.

A simpler explanation is that suicide terrorism is not altruistic but rather reflects individual suicidal tendencies (Merari et al., 2009; Lankford, 2013ba). Common suicidal behavior is less challenging for both rational and evolutionary 
perspectives. Individuals who have a low expected utility over their lifetime may rationally commit suicide (Hamermesh \& Soss, 1974). From an evolutionary perspective, suicide may be explained by kin selection: individuals who have low prospect of reproduction and consider themselves to be a burden for kin relatives may engage in self-destruction (Brown et al., 2009, 1999, de Catan-

35 zaro 1995). Thus, a possibility is that suicide terrorists engage in violence for the same reasons than non-suicide terrorists, but that the specific decision to commit suicide or non-suicide missions reflects individual differences in suicidal tendencies.

\section{Existing evidence}

Despite passionate debates on whether suicide terrorists are suicidal (see Lankford, 2014, Atran, 2014, Sela \& Shackelford, 2014, Atran, 2004, McCauley, 2014), evidence insofar remains scarce (see Sheehan, 2014). Assessing suicidal tendencies of suicide terrorists is methodologically challenging. Researchers can hardly apply clinical evaluations of candidates for suicide terrorism. One notable exception is Merari et al. (2009) who conducted psychological tests on fifteen Palestinian prisoners who attempted to commit a suicide attack, in comparison to prisoners who committed other types of attacks or organized suicide attacks. Their diagnoses indicated that perpetrators of suicide attacks displayed higher avoidant-dependent personality disorders, depressive symptoms and suicidal tendencies. However, it is impossible to disentangle whether the suicidal tendencies of the subjects preceded or followed the attack. Suicidal tendencies could reflect the hard conditions of incarceration and the psychological cost of the failure to achieve the attack (Brym \& Araj, 2012b).

In response to Merari et al. (2009), Brym \& Araj (2012a) conducted interviews with family members of fourty Palestinians who committed suicide attacks. Their findings differed from those Merari et al. (2009). In the year before the attacks, three-quarter of individuals did not show signs of depression or personal crisis according to their relatives. Nonetheless, interviews with family 
members encompass reliability issues, since they may be unaware of the psychological state and prone to picture their relatives in a more or less favorable light depending on their approval of suicide terrorism (see Merari, 2010, 83-102). For instance, Speckhard \& Ahkmedova (2006) drew opposite conclusion based on interviews of close relatives of 34 Chechen suicide bombers. In their case, the interviews indicated that all individuals experienced the death or beating of close parents or friends prior to their involvement, which resulted in symptoms of post-traumatic stress in all cases, social alienation and isolation in nearly all cases and depression in around $60 \%$ of cases.

Another line of research relies on biographical data derived from public sources to assess the prevalence of established suicide risk factors among suicide terrorists. Using this approach, Lankford (2013b) found clues of suicide risk factors in nearly 130 suicide terrorists around the world: including, depressive disorders, post-traumatic stress disorder or other associated mental disorders, the death of a spouse or loved one, or negative catalyst events. In another study focusing on the United States from 1990 to 2010, Lankford (2013a) compared the characteristics of suicide terrorists and rampage, workplace and school shooters, generally associated with mental disorders (Langman, 2009, 2013). Lankford (2013a) found high level of similarities between groups in terms of social and personal issues preceding the attack. However, as these studies were based on the researchers' evaluation of social and mental problems faced by the terrorists based on fragmentary data, one cannot exclude coding biases (Atran, 2014). Besides, they lacked a control group of non-suicide terrorist, which would be necessary to gauge the specificity of suicide terrorists compared to non-suicide terrorists. It is possible that risk factors commonly associated to suicidal tendencies play a more general role in radicalization processes leading both to suicide and non-suicide terrorism. For instance, some evidence suggests that depression is related to vulnerability to radicalization (Bhui et al., 2014).

To our knowledge, only one study addressed these issues. Freilich et al. (2019) compared a sample of 56 suicide terrorists to 391 non-suicide terrorists based on a collective open-source database of perpetrators of terrorist attacks 
in the United States (Freilich et al., 2014). They measured suicidal tendencies based on evidence that terrorists had been diagnosed mentally ill or had previously attempted suicide. Albeit a higher proportion of suicide terrorists entered this category, the difference was not significant. Freilich et al. (2019) also found that suicide terrorists were significantly more likely to have a known history of alcohol/drug abuse, a secondary proxy of suicidal risk factors. In sum, their results indicated limited support for the suicidality hypothesis.

The study of Freilich et al. (2019) had some limitations that required further investigation. First, a majority of the sample was based on a broad definition of suicide terrorism including individuals who did not commit suicide but presumably expected to die during the attack 11 Among the 25 remaining cases in which suicide was an inherent part of the attack, 19 were the hijackers of the 9/11 attacks. Since these individuals were non-US citizens, one can wonder whether the probability of clinical diagnoses for mental illness and the availability of information on previous suicidal attempts was comparable to the rest of the sample. In such cases, absence of evidence may not be evidence of absence 2 Hence, it is necessary to replicate the analysis of Freilich et al. (2019) based on different samples and operationalization of suicide terrorism, and to account for differences in available information across cases.

\footnotetext{
${ }^{1}$ The expectation to die in the attack may be disputed in some cases analyzed by Freilich et al. (2019). For instance, the sample included the perpetrator of the shootings at the CIA headquarters in 1993 who escaped in Pakistan after the attack and was later captured and sentenced to death. It also included the perpetrator of the Oklahoma city bombing in 1995 who was captured in the aftermath of the attack and sentenced to death.

${ }^{2}$ On this regards, Lankford (2018) re-examined evidence of mental illness among the hijackers of the 9/11 attacks. For most (13) cases, existing biographical evidence was too scarce to allow any psychological assessment. In the other cases, Lankford (2018) found evidence of mental health problems that may relate to suicidal tendencies.
} 


\section{Overview of studies}

110 relied on a new reliable open-source database on domestic terrorists who radicalized in the United States from 1948 to 2017. The study compared the prevalence of a range of established suicide risk factors in a sample of narrowly defined suicide terrorists $(N=20)$ compared to non-suicide terrorists $(N=1,214)$, con-

\footnotetext{
${ }^{3}$ This estimation is based on countries with populations greater than 1 million, which excludes random outlier cases (Naghavi, 2019).
} 


\section{Study 1}

\subsection{Methods}

\subsubsection{Data}

Study 1 relied on the Profiles of Individual Radicalization in the United States (PIRUS) database, developed by the University of Maryland (National Consortium for the Study of Terrorism and Responses to Terrorism (START), 2018). The data is based on public sources and gathers a representative sample of more than 2,100 profiles of radical activists in the United States from 1948 to 2017. To be included, individuals must have perpetrated ideologically motivated illegal acts or have been a known members of organizations designated as terrorists and / or whose leader has committed ideologically motivated violence. Besides, individuals must have been radicalized in the United States. The PIRUS database results from a collective coding effort and tests on double-coded samples of the database indicated that the data respects common standards of inter-coder reliability ( LaFree et al., 2018).

n The PIRUS database is complementary with the data analyzed by Freilich et al. (2019). Firstly, the time span of the present data is larger than Freilich et al. (2019). Secondly, the PIRUS database focuses on individuals who radicalized in the United States, but who may have committed ideologically motivated crime elsewhere ${ }^{4}$ Finally, the PIRUS database includes a larger set of biographical information on perpetrators which allow new insights about suicide risk factors.

\subsubsection{Suicide versus non-suicide terrorists}

I first excluded individuals who did not actively participate in a plot involving violence. In the remaining sample of terrorists $(N=1,241)$, I identified suicide terrorists, narrowly defined as individuals who committed suicide in

\footnotetext{
${ }^{4}$ In contrast, Freilich et al. (2019) focused on individuals who perpetrated ideologically motivated crimes in the United States, even if they radicalized elsewhere - such as in the case of the $9 / 11$ attacks.
} 
perpetrating violence. The PIRUS database does not directly identify suicide terrorists. To do so, I first selected individuals that were currently dead due to suicide $(\mathrm{N}=35)$. I then conducted research for each case based on public sources to specifically identify suicide terrorists. Among, the 35 suicide cases, I identified 20 cases as suicide terrorists. This included 5 suicide bombers, 2 plane hijackers, and 13 individuals who committed suicide while or directly after perpetrating firearm violence. Among the remaining 15 cases, 9 committed suicide long ago after perpetrating violence, whom I included in the non-suicide terrorist category. ${ }^{5}$ I was not able to find information on the six remaining cases and excluded them from the analyses $6^{6}$ As a result, I obtained a group of suicide terrorists $(\mathrm{N}=20,1.6 \%$ of the sample), which can be compared to non-suicide terrorists $(\mathrm{N}=1,214)$.

\subsubsection{Suicide risk factors}

I screened variables related to personal characteristics of terrorists in the PIRUS database to identify all measures that may capture established suicide risk factors based on scientific research on suicidality.

Child abuse. Meta-analytic evidence demonstrates that individuals that were abused as child are at significantly higher risk of suicide attempt: three times more likely in case of sexual abuse and two and a half more likely in case of physical or emotional abuse (Angelakis et al., 2019, Dube et al. 2001, Bruffaerts et al. 2010). I relied on the following question: "Is there evidence that the individual was abused - either verbally or physically - as a child? If there is no information, assume 0 for No". I generated a binary variable coded $0=$ no evidence of abuse (1,184 cases; $96 \%$ of valid cases), $1=$ evidence of abuse (50 cases; $4 \%$ of valid cases).

\footnotetext{
${ }^{5}$ Note that the inclusion of these cases in the suicide terrorist category does not alter the conclusions. Results can be sent by the author upon request.

${ }^{6}$ Note that the inclusion of these cases in the suicide or in the non-suicide terrorist category does not alter the conclusions. Results can be sent by the author upon request.
} 
History of mental illness. There is a strong correlation between mental disorders and suicidal behaviors (Nock et al. 2008, Cavanagh et al., 2003), albeit the intensity of the relationship depends on the kind of mental disorders: mood disorders, especially depression, being stronger predictors than other disorders (Kessler et al., 1999). Unfortunately, the PIRUS database does not include information on specific mental disorders. I assessed the experience of any mental disorder based on the following question: "Is there evidence presented in the sources that the individual had a history of mental illness? If there is no information, assume 0 for No". I generated a binary variable coded $0=$ no evidence of mental illness (1,051 cases; $85 \%$ of valid cases), $1=$ evidence of mental illness either according to public/popular speculation or professionally diagnosed (183 cases; $15 \%$ of valid cases).

Relationship troubles. Social isolation - either living alone or loneliness feelings 195 - is related to suicidal behaviors (Calati et al. 2019), and psychological autopsies reveal enhanced chronic and recent relationship problems among individuals who committed suicide (Appleby et al. 1999, Houston et al., 2001). I relied on the following question: "Did subject typically have difficulty finding or maintaining romantic relationships?". I generated a binary variable coded missing for cases in which the response was unknown (833 cases), $0=$ no troubles (290 cases; $72 \%$ of valid cases), $1=$ troubles (111 cases; $28 \%$ of valid cases).

Absent parent/s. Household dysfunction during childhood, including parents' separation, has been shown to increase the risk of attempted suicide in later life (Dube et al. 2001). Notably, parent loss, either due to death, divorce or other causes, is related to subsequent suicidal behaviors (Bruffaerts et al. 2010). I relied on the following question: "Are/were there any parents absent (separated, divorced, killed, suicide, or dead of natural causes?) during the individual's childhood?". I generated a binary variable coded missing for cases in which the response was unknown (901 cases), $0=$ no parenthood absence 210 ( 220 cases; $66 \%$ of valid cases), 1 = parenthood absence - either father, mother or both (113 cases; $34 \%$ of valid cases). 
History of alcohol/drug abuse. Substance abuse is a common correlate of suicidal behaviors (Adams \& Overholser, 1992), especially alcohol acute use (Cherpitel et al. 2004). I relied on the following question: "Is there evidence presented in the sources that the individual had a history of alcohol or drug abuse? If there is no information, assume 0 for No". I generated a binary variable coded $0=$ no evidence of alcohol/drug abuse (1,071 cases; $87 \%$ of valid cases), $1=$ evidence of alcohol/drug abuse (163 cases; $13 \%$ of valid cases).

Trauma. There is evidence that the personal experience of some traumatic events - such as sexual and interpersonal violence - increases suicide ideations and, in some cases, suicide attempts (Stein et al. 2010). I relied on the following question: "Prior to radicalization, was subject ever exposed to any traumatic event in which he witnessed an event or events that involve actual or threatened death or serious injury, or a threat to the physical integrity of others, where his response involved intense fear, helplessness, or horror?". I generated a binary variable coded missing for cases in which the response was unknown (908 cases), $0=$ no trauma (206 cases; $63 \%$ of valid cases), $1=$ trauma (120 cases; $37 \%$ of valid cases).

\subsubsection{Other individual factors}

230 Sociodemographic and personal characteristics. I tested the effect of a range of characteristics usually included in analyses of profiles of terrorists (Freilich et al. 2019, LaFree et al., 2018). Four variables captured demographic characteristics. I used a continuous variable measuring the age of the perpetrator at the time of the plot $(M=33$, s.d. $=13)$, with 28 missing cases. For gender, I used a binary variable coded $0=$ female ( 84 cases; $7 \%$ of valid cases), $1=$ male (1,150 cases; $93 \%$ of valid cases). I measured minority status, based on the ethnicity of the individual, by a binary variable coded missing for cases in which the ethnicity was unknown ( 89 cases), $0=$ white ( 694 cases; $61 \%$ of valid cases), $1=$ other (451 cases; $39 \%$ of valid cases). I identified immigrant individuals with a binary

variable coded missing for cases in which the residency status was unknown (62 
cases), $0=$ born citizen ( 1,018 cases; $87 \%$ of valid cases $), 1=$ naturalized citizen or resident (154 cases; $13 \%$ of valid cases).

Two variables captured previous involvement in violence and crime. I generated a binary variable to assess military experience coded missing for cases in which there was no information about military experience (382 cases), $0=$ never in the US or a foreign military ( 716 cases; $84 \%$ of valid cases), $1=$ ever was in the US or a foreign military (136 cases; $16 \%$ of valid cases). I identified individuals with previous criminal activity with a binary variable coded missing for cases in which there was no information (483 cases), $0=$ no history of criminal activity prior to radicalization ( 407 cases; $54 \%$ of valid cases), $1=$ history of criminal activity prior to radicalization (344 cases; $46 \%$ of valid cases).

Two variables captured the social background of individuals. I measured the education level by a categorical variable coded missing for cases in which there was no information (712 cases), $0=$ Less than high school (87 cases; $17 \%$ of valid cases), $1=$ high school diploma ( 136 cases; $26 \%$ of valid cases), $2=$ more than high school (299 cases; $57 \%$ of valid cases). I measured the individuals' social stratum as adulthood by a categorical variable coded missing for cases in which there was no information (635 cases), $0=$ Low 7 ( 49 cases; $8 \%$ of valid cases), $1=$ Middl 8 (368 cases; $61 \%$ of valid cases), $2=$ High 9 (182 cases; $30 \%$ of valid cases).

Ideology. Some studies suggested that Islamist ideologies specifically provide beliefs that help reducing the cost of killing and dying in suicide missions (Perry \& Hasisi, 2015, Moghadam, 2009). I measured the terrorist's ideology based on a categorical variable coded $0=$ far-left (120 cases; $11 \%$ of valid cases), $1=$

\footnotetext{
${ }^{7}$ E.g. receives welfare, lives close to the poverty line, regularly unemployed or at best works a blue collar job, lives in subsidized housing.

${ }^{8}$ E.g. does not receive welfare, lives in lower-middle or middle class neighborhood, has steady professional employment, owns or holds a mortgage on a house, has college degree.

${ }^{9}$ E.g. works a high-income, white-collar job, lives and owns a house in a middle or upper class neighborhood, can afford luxury items, has college degree or is self-employed as a successful entrepreneur.
} 

cases), and missing otherwise.

Lone. Some studies indicated that lone terrorists have a distinct psychological profile than terrorists affiliated to a group (Gruenewald et al. 2013, Gill et al. 2014). Lone terrorists generally display higher prevalence of mental disorders rates of mental disorders (Corner \& Gill, 2015, Corner et al., 2016, Corner \& Gill 2017). Lone terrorists are also more likely to be socially isolated than affiliated terrorists (Gill et al., 2014, Gruenewald et al., 2013, Capellan, 2015). Besides, previous evidence indicated that lone terrorists were more likely to engage in

2019). Hence, it was possible that the suicide risk factors under study related to lone terrorism rather than suicide terrorism. I relied on the following question: "Was the individual in a group?". I generated a binary variable coded $0=$ affiliated terrorist - either member of an above-ground political movement or activist group, an informal group of fellow extremists or a formal extremist organization or an extremist movement (932 cases; $76 \%$ of valid cases), $1=$ lone actor (302 cases; $24 \%$ of valid cases).

\subsubsection{Empirical strategy}

The small size of the sample of suicide terrorists prevented to conduct ex285 tensive multivariate analyses, which would require larger degrees of freedom. For that reason, I conducted statistical analyses in an ascendant method. I firstly focused on bivariate analyses. Then, I computed multivariate analyses for each significant suicide risk factor, controlling for the other factors that were significant in bivariate analyses.

Differences in available information. A common limitation of data based on public sources is that the available information varies across cases. The lack of information resulted in missing values for most variables under study. I excluded observations with missing values by listwise deletion in the analyses. 
This decision is conservative: this eliminates potential biases due to unequal terrorists. Fisher's exact tests revealed that, over the six suicide factors, four were significantly related to suicide terrorism at the $5 \%$ threshold. The prevalence of child abuse among suicide terrorist was $20 \%$ (4/20), compared to $4 \%$ $(46 / 1,214)$ among non-suicide terrorists $(p=.007) .35 \%(7 / 20)$ of suicide terror-

\footnotetext{
${ }^{10}$ For instance, it is possible that suicide terrorists received more media attention than non-suicide terrorists, resulting in more available information about them and hence a higher probability that a history of child abuse would be detected among suicide terrorists.

${ }^{11} \mathrm{I}$ doing so, I assumed that missing values were not randomly distributed across cases: that is, that there was a positive correlation within cases in the likelihood of missing values for different variables. Evidence confirmed that this assumption was true. I computed two indicators of the share of non-missing values each for half of the PIRUS database variables. Results of the Pearson correlation showed that these indicators were strongly correlated, $r(1232)=0.77, p<.000$. This means that individuals with missing values for some variables were more likely to have missing values for other variables.
} 
terrorists $(p=.020)$. The prevalence of relationship troubles among suicide terrorist was $67 \%(8 / 12)$, compared to $26 \%$ (103/389) among non-suicide terrorists $(p=.005)$. Finally, $67 \%(8 / 12)$ of suicide terrorists had absent parent/s, compared to $33 \%(105 / 321)$ of non-suicide terrorists $(p=.025)$.

320 suicide terrorism. None of the sociodemographic and personal characteristics were significantly different among suicide and non-suicide terrorists. The proportion of individuals who engage in suicide terrorism did not differ by ideology, $\chi^{2}(2, N=1,046)=3.13, p=.209$. The proportion of lone actors was not signif$24 \%(294 / 1,214)$ among non-suicide terrorists $(p=.117){ }^{12}$ Except suicide risk factors, the only factor that was significantly associated with suicide terrorism was the share of valid values. There was a significant higher share of valid values in the PIRUS database for suicide terrorists $(M=74$, s.d. $=20)$ compared to non-suicide terrorists $(M=64$, s.d. $=15), t(1232)=2.64, p=.008$.

Table 2 presents estimates from logistic regressions of suicide terrorism. I tested the effect of the four suicide risk factor that were significant in bivariate analyses, controlling for the share of valid values ${ }^{13}$ Results from model (1) confirmed that child abuse was significantly related to suicide terrorism. In contrast, history of mental illness was no longer significantly related to suicide terrorism at the $5 \%$ threshold when controlling for the share of valid values. This suggests that the higher prevalence of mental illness among suicide terrorists partly reflected the greater available information about them. Finally, models (3) and (4) confirmed that suicide terrorists were significantly more likely to

\footnotetext{
${ }^{12}$ Note that the difference in the proportion of lone actors between suicide and non-suicide terrorists was significant at the $10 \%$ threshold $(\mathrm{p}=.090)$ under the assumption of a one-tailed test.

${ }^{13} \mathrm{I}$ also tested the same models controlling for lone actor, as this variable was close to statistical significance in bivariate analyses. The results were unchanged. Results can be sent by the author upon request.
} 
Table 1: Distribution of variables across non-suicide and suicide terrorists and bivariate statistical tests

\begin{tabular}{|c|c|c|c|}
\hline & $\begin{array}{l}\text { Non-suicide } \\
(N=1,214)\end{array}$ & $\begin{array}{l}\text { Suicide } \\
(N=20)\end{array}$ & $p$-value \\
\hline \multicolumn{4}{|l|}{ Suicide risk factors } \\
\hline Child abuse & $4 \%$ & $20 \%$ & .007 \\
\hline History of mental illness & $14 \%$ & $35 \%$ & .020 \\
\hline Relationship troubles & $26 \%$ & $67 \%$ & .005 \\
\hline Absent parent/s & $33 \%$ & $67 \%$ & .025 \\
\hline History of alcohol/drug abuse & $13 \%$ & $25 \%$ & .170 \\
\hline Trauma & $36 \%$ & $50 \%$ & .472 \\
\hline \multicolumn{4}{|l|}{ Other factors } \\
\hline Mean age (s.d.) & $33(13)$ & $30(12)$ & .461 \\
\hline Gender & $93 \%$ & $95 \%$ & 1.000 \\
\hline Minority status & $40 \%$ & $28 \%$ & .344 \\
\hline Immigrant & $13 \%$ & $17 \%$ & .721 \\
\hline Military experience & $16 \%$ & $19 \%$ & .730 \\
\hline Previous criminal activity & $46 \%$ & $56 \%$ & .453 \\
\hline Education & & & .532 \\
\hline Less than high school & $16 \%$ & $22 \%$ & \\
\hline High school diploma & $26 \%$ & $33 \%$ & \\
\hline More than high school & $58 \%$ & $44 \%$ & \\
\hline Social stratum & & & .907 \\
\hline Low & $8 \%$ & $7 \%$ & \\
\hline Medium & $62 \%$ & $57 \%$ & \\
\hline High & $30 \%$ & $36 \%$ & \\
\hline Ideology & & & .209 \\
\hline Far-left & $12 \%$ & $0 \%$ & \\
\hline Far-right & $53 \%$ & $68 \%$ & \\
\hline Islamist & $35 \%$ & $32 \%$ & \\
\hline Lone & $24 \%$ & $40 \%$ & .117 \\
\hline Mean share of valid values (s.d.) & $64(15)$ & $74(20)$ & .008 \\
\hline
\end{tabular}


Table 2: Odds ratios from logistic regression analyses of suicide terrorism (versus non-suicide terrorism)

\begin{tabular}{|c|c|c|c|c|}
\hline & $(1)$ & $(2)$ & $(3)$ & $(4)$ \\
\hline \multirow[t]{2}{*}{ Child abuse } & $4.143^{*}$ & & & \\
\hline & $(2.525)$ & & & \\
\hline \multirow[t]{2}{*}{ History of mental illness } & & $2.390^{+}$ & & \\
\hline & & $(1.172)$ & & \\
\hline \multirow[t]{2}{*}{ Relationship troubles } & & & $5.425^{* *}$ & \\
\hline & & & $(3.403)$ & \\
\hline \multirow[t]{2}{*}{ Absent parent/s } & & & & $4.037^{*}$ \\
\hline & & & & $(2.548)$ \\
\hline \multirow[t]{2}{*}{ Share of valid values } & $1.032^{*}$ & $1.034^{*}$ & $1.055^{*}$ & $1.087^{*}$ \\
\hline & $(0.0162)$ & $(0.0162)$ & $(0.0288)$ & $(0.0383)$ \\
\hline Observations & 1234 & 1234 & 401 & 333 \\
\hline Pseudo $R^{2}$ & 0.0553 & 0.0481 & 0.117 & 0.125 \\
\hline
\end{tabular}

Standard errors in parentheses

$+p<0.10,{ }^{*} p<0.05,{ }^{* *} p<0.01,{ }^{* * *} p<0.001$

Sample size varies across models due to listwise deletion

\subsubsection{Secondary analyses}

A secondary question is whether suicidal tendency explain not only why individuals directly commit suicide but also why individuals take extreme risks with their life in perpetrating violence. To explore this possibility, I conducted similar analyses on a secondary sample of near-suicide terrorists, i.e. individuals who presumably expected to be killed in perpetrating violence.

I selected in the sample of non-suicide terrorists all individuals that had been killed, either by authorities or rival groups $(N=81)$. I conducted research based on public sources to identify all cases in which individuals presumably 
suicide terrorists. In all cases, individuals were killed as a result of their violent action by violently resisting arrest. Among the remaining cases, I included 17 cases in the non near-suicide category because evidence did not indicate that the perpetrators expected to be killed ${ }^{14}$ I excluded the remaining 38 cases because evidence did not allow to assess whether the individual expected to be killed in perpetrating violence ${ }^{15}$ As a result, I obtained a group of near-suicide terrorists $(N=26)$, which can be compared to non near-suicide terrorists $(N=1,150)$.

Table A.4 presents the distribution of variables across non near-suicide and near-suicide terrorists. Fisher's exact tests revealed that, over the six suicide factors, only one was significantly related to near-suicide terrorism. The prevalence of child abuse among suicide terrorist was $23 \%$ (6/26), compared to $3 \%$ $(40 / 1,150)$ among non-suicide terrorists $(p=.000)$. Bivariate tests revealed that none of the other factors were significantly related to near-suicide terrorism, except the share of valid values 16 There was a significant higher share of valid values in the PIRUS database for near-suicide terrorists $(M=80$, s.d. $=12)$ compared to non near-suicide terrorists $(M=64$, s.d. $=15), t(1174)=5.27$, $p=.000$.

Table A.5 presents estimates from logistic regressions of near-suicide terrorism. I tested the effect of child abuse, controlling for the share of valid values ${ }^{17}$ Results from model (1) confirmed that child abuse was significantly related to

\footnotetext{
${ }^{14}$ This included 7 individuals killed afterward by capital punishment, 3 shot by authorities without having opposed resistance, 3 killed by military strikes, 2 killed in shootouts while escaping after a robbery and 2 assassinations.

${ }^{15}$ This included cases for whom I did not find information and cases for whom information did not allow to evaluate whether the individual expected to be killed in action - such as cases of foreign fighters who died in fights with rival groups in unknown circumstances.

${ }^{16}$ Two other factors were significant at the $10 \%$ threshold. Near-suicide terrorists differed from non near-suicide terrorists by ideology, $\chi^{2}(2, N=991)=4.68, p=.096$. Besides, Fisher's exact test revealed that the proportion of lone actors was different among near-suicide compared to non near-suicide terrorists $(p=.082)$, under the assumption of a one-tailed test.

${ }^{17} \mathrm{I}$ also tested the same models controlling for ideology and lone actor, as these variables were close to statistical significance in bivariate analyses. The results were unchanged. Results can be sent by the author upon request.
} 
near-suicide terrorism.

\subsection{Discussion}

Study 1 analyzed whether suicide terrorists were more likely to exhibit established suicidal risk factors than non-suicide terrorists based on a represen-

tative sample of domestic terrorists from the United States between 1948 and 2017. Overall, results are consistent with the hypothesis that suicide terrorism is related to common suicidal tendencies. Over the six suicide risk factors under study, three were significantly related with suicide terrorism when controlling for the difference in available information across cases. Namely, I found that suicide terrorists were four times more likely to have been abused as children, five times more likely to have had a history of relationship troubles and four times more likely to have experienced absent parenthood. In contrast, no significant difference were found on sociodemographic characteristics, previous involvement in violence and crime, ideology and group membership. This indicates that differences in suicide risk factors were not a mere artifact due to confounding factors or samples heterogeneity. Besides, this supports the view that suicide terrorists follow similar patterns of radicalization to non-suicide terrorists, and that the specific decision to commit suicide or non-suicide missions reflects individual differences in suicidal tendencies.

390 The present results must be interpreted in light of the small size of the sample of suicide terrorists. Some differences between suicide terrorists and non-suicide terrorists may have not been detected due to lack of statistical power. This may be true for sociodemographic and personal factors. In this regards, Sabri \& Schulze (2020) recently compared the sociodemographic profiles of suicide and non-suicide terrorists of the Hamas and Palestinian Islamic Jihad based on a large sample gathering more than 200 suicide terrorists. Their results revealed differences between groups in age, education and familial status.

This consideration may also be true for suicide risk factors. One cannot exclude that non-significant suicide risk factors in the present study actually play a role in suicide terrorism. It is worth noticing that even when non-significant, 
all the suicide risk factors under study were related with suicide terrorism in the expected direction. The possibility that suicidal tendencies were undetected in some cases is even more likely as regards to the fact that established suicide risk factors generally have a limited predictive power and that half of suicides occur among people who would be viewed as low risk (Franklin et al., 2017, Large et al. 2017). Symmetrically, the fact that three suicide risk factors were found significant despite low statistical power suggests that suicidal tendencies play a crucial role in suicide terrorism.

A secondary finding was that, over the six suicide risk factors under study, only one - child abuse - was higher among terrorists who presumably expected to be killed in perpetrating violence. On the one hand, this result may be interpreted as a confirmation, from a second sample, that suicidal tendencies play a role in suicide terrorism, broadly defined as "the readiness to die in the process of committing a terrorist act" (Merari, 1990). Indeed, among the suicide risk factors under study, child abuse may be considered as one of the most predictive (Franklin et al., 2017, Angelakis et al. , 2019). On the other hand, the absence of significant effects of other suicide risk factors suggests that suicidal tendencies play a lesser role in the decision to engage in action with readiness of being killed, compared to the decision to directly commit suicide in action. This suggests that there is a difference between knowingly sacrificing one's life and taking risks with one's life - even with a low probability to survive. This may partly explain why Freilich et al. (2019) found limited support for the suicidal hypothesis when analyzing suicide terrorism based on a broad definition.

In addition to the low sample size, the main limitation of Study 1 is the impossibility to generalize the results outside the US case. In particular, one may wonder whether the results are also valid in countries in which suicide terrorism receive a higher support from "constituent" communities (Ginges et al., 2009) and is used by well-implanted terrorist groups (Pape, 2006). To generalize the findings, Study 2 analyzed the relationship between cross-national variation in 430 suicide tendencies and variations in suicide and non-suicide terrorist attacks. 


\section{Study 2}

\subsection{Methods}

\subsubsection{Suicide and non-suicide attacks}

․ Study 2 relied on the Global Terrorism Database (GTD) National Consor-

435 tium for the Study of Terrorism and Responses to Terrorism (START), 2017) collected by the University of Maryland. It is currently the most comprehensive open-source database on all terrorist attacks worldwide since 1970. The GTD includes all violent incidents intentionally perpetrated by sub-national actors to attain a political aim, outside the context of legitimate warfare categories, with the intention to influence a broader audience. Among these terrorist attacks, the GTD identifies suicide attacks as cases in which there is "evidence that the perpetrator did not intend to escape from the attack alive". I constructed two dependent variables, respectively the number of suicide attacks and the number of non-suicide attacks by country and year according to the GTD.

\subsubsection{Independent variables}

Suicidal tendencies. I measured the prevalence of suicidal tendencies by country and year by the share of deaths from suicide from the Global Burden of Dispase Study (GBD) covering 195 countries from 1990 to 2016 Global Burden of Disease Collaborative Network, 2018). The GBD is currently the most accurate source for cross-national estimates on deaths from suicide (Naghavi, 2019).

Control variables. I controlled for a range of confounding factors that may affect both the number of suicide and non-suicide attacks, according to research on the cross-national causes of terrorism (Kis-Katos et al., 2011; Freytag et al. 2011, Choi \& Piazza, 2016, Piazza, 2017; Ghatak et al., 2019, Krueger, 2017).

The log of the population size was expected to increases the number of attacks. The share of discriminated population, derived from the Ethnic Power Relations database (Vogt et al. 2015), was expected to increase the number of attacks. The level of democracy was expected to increase the number of attacks. I used the composite scale from -10 (autocracy) to 10 (democracy) of the Polity dataset 

to decrease the number of attacks. Civil war, measured in magnitude from 0 to 10 (Center for Systemic Peace, 2018a), was expected to increase the number of attacks. The log of the Gross Domestic Product (GDP) per capita was expected to increase the number of attacks

Some studies found that Muslim majority countries experience a higher number of suicide terrorist attacks (Wade \& Reiter, 2007, Choi \& Piazza, 2017). Following these studies, I controlled for the share of Muslim population based pn quadrennial estimates from the World Religion Dataset (Maoz \& Henderson, 2013). Besides, it has been argued that suicide terrorism is especially used as an asymmetric warfare strategy against foreign military occupation (Pape 2006), even though evidence on this matter is disputed (Choi \& Piazza, 2017 Moghadam, 2006). I generated a binary variable capturing instances of foreign occupation based on the list of foreign military occupations assembled for the 1950-2013 period by Vishwasrao et al. (2019).

\subsubsection{Empirical strategy}

All variables are described in Table A.6. The analyzed sample includes 137 countries over the 1991-2014 period.18 I analyzed the number of suicide and non-suicide attacks by country and year based on negative binomial regression models, the standard method in studies analyzing counts of terrorist attacks Choi \& Piazza, 2017, 2016, Piazza, 2017, Kis-Katos et al., 2011; Freytag et al. 2011, Ghatak et al., 2019). To compare the effects of the independent variables on the number of suicide attacks and the number of non-suicide attacks, I computed the same models on both dependent variables. I tested a main model including all independent variables, and a second model including country and year fixed effects to control for potential unmeasured national and historical factors. To infer causality, the independent variables were one-year lagged.

\footnotetext{
${ }^{18}$ The lower limit of the study period is due on the lack of data on the share of deaths from suicide before 1990 .
} 


\subsection{Results}

\subsubsection{General comments}

The GTD recorded a total of 1,634 suicide attacks (2,5\% of all attacks) and 63,200 non-suicide attacks in the sample 19 Both suicide and non-suicide attacks were concentrated in specific countries. Iraq experienced in 2014 both the higher number of suicide attacks $(236)$ and non-suicide attacks $(3,133)$. In contrast, $93 \%$ of countries did not experienced any suicide attacks during a given year ( $44 \%$ for non-suicide attacks). A Spearman correlation indicated that the number of suicide and non-suicide attacks were significantly related, $r_{s}=0.31, p=.000$.

\subsubsection{Main results}

Table 3 presents results from regression models. The dependent variable is the number of suicide attacks in models (1) and (2). Results from model (1) indicated that the share of deaths from suicide was positively and significantly related to the number of suicide attacks. The effect of the share of deaths from suicide was still significant in model (2) including country and year fixed effects. Models (3) and (4) are the same than models (1) and (2) except that the dependent variable is the number of non-suicide attacks. Results from model (3) indicated that the share of deaths from suicide was not significantly related to the number of non-suicide terrorist attacks. The coefficient was still insignificant in model (4) including country and year fixed effects 20

\footnotetext{
${ }^{19}$ Note that the sample excluded Afghanistan due to lack of data about the level of democracy. Afghanistan experienced a high number of suicide attacks (731) and non-suicide attacks $(5,786)$ in the study period. The inclusion of Afghanistan raised the total number of suicide attacks to 2,365. I computed the analyses including Afghanistan in the sample - excluding the democracy variable. The results were unchanged. Results can be sent by the author upon request.

${ }^{20}$ The number of observations is lower in models (2) and (4) because they exclude countries which experienced no suicide attacks in the study period. Indeed, these cases were perfectly predicted by the country fixed effects in model (2). To ensure sample comparability between model (2) and (4), These cases were also excluded from the sample analyzed in model (4).
} 
Table 3: Unstandardized coefficients from negative binomial analyses of the number of terrorist attacks

\begin{tabular}{|c|c|c|c|c|}
\hline \multirow{4}{*}{$\begin{array}{l}\text { Dependent variable } \\
\text { Share of deaths from suicide } t-1\end{array}$} & (1) & $(2)$ & $(3)$ & (4) \\
\hline & \multicolumn{2}{|c|}{ Suicide attacks } & \multicolumn{2}{|c|}{ Non-suicide attacks } \\
\hline & $1.149^{* * *}$ & $0.993^{* *}$ & 0.0204 & -0.343 \\
\hline & $(0.105)$ & $(0.380)$ & $(0.0401)$ & $(0.180)$ \\
\hline \multirow[t]{2}{*}{ Share of Muslim $t-1$} & $5.715^{* * *}$ & -14.51 & $0.559^{* * *}$ & -4.241 \\
\hline & $(0.404)$ & $(10.30)$ & $(0.138)$ & $(3.039)$ \\
\hline \multirow[t]{2}{*}{ Log GDP per capita $t-1$} & $0.468^{* * *}$ & $1.742^{* * *}$ & 0.0293 & 0.179 \\
\hline & $(0.102)$ & $(0.425)$ & $(0.0369)$ & $(0.139)$ \\
\hline \multirow[t]{2}{*}{ Log Population $_{t-1}$} & $1.145^{* * *}$ & $7.712^{* * *}$ & $0.985^{* * *}$ & $3.204^{* * *}$ \\
\hline & $(0.0931)$ & $(2.227)$ & $(0.0359)$ & $(0.592)$ \\
\hline \multirow[t]{2}{*}{ Discriminated population $_{t-1}$} & $9.117^{* * *}$ & $7.479^{*}$ & $1.828^{* * *}$ & -1.549 \\
\hline & $(0.977)$ & $(2.923)$ & $(0.405)$ & $(0.875)$ \\
\hline \multirow[t]{2}{*}{ Democracy $t-1$} & $0.129^{* * *}$ & 0.0343 & $0.0799^{* * *}$ & 0.0293 \\
\hline & $(0.0280)$ & $(0.0391)$ & $(0.00995)$ & $(0.0163)$ \\
\hline \multirow[t]{2}{*}{ Regime durability $t-1$} & $-0.0106^{* *}$ & $-0.0323^{*}$ & $-0.0110^{* * *}$ & $-0.0146^{* *}$ \\
\hline & $(0.00377)$ & $(0.0140)$ & $(0.00156)$ & $(0.00527)$ \\
\hline \multirow[t]{2}{*}{ Civil war $t-1$} & $0.437^{* * *}$ & $0.336^{*}$ & $0.388^{* * *}$ & $0.313^{* * *}$ \\
\hline & $(0.128)$ & $(0.153)$ & $(0.0548)$ & $(0.0599)$ \\
\hline \multirow[t]{2}{*}{ Foreign military occupation $t-1$} & 0.391 & 0.186 & $0.496^{*}$ & $1.091^{*}$ \\
\hline & $(0.608)$ & $(1.022)$ & $(0.234)$ & $(0.491)$ \\
\hline \multirow[t]{2}{*}{ Constant } & $-29.63^{* * *}$ & $-135.3^{* * *}$ & $-14.68^{* * *}$ & $-46.97^{* * *}$ \\
\hline & $(1.951)$ & $(39.23)$ & $(0.632)$ & $(10.39)$ \\
\hline \multirow[t]{2}{*}{ lnalpha } & $2.460^{* * *}$ & $0.516^{* * *}$ & $1.486^{* * *}$ & $-0.117^{*}$ \\
\hline & $(0.0951)$ & $(0.140)$ & $(0.0303)$ & $(0.0560)$ \\
\hline Country fixed effects & No & Yes & No & Yes \\
\hline Year fixed effects & No & Yes & No & Yes \\
\hline Observations & 2971 & 1094 & 2971 & 1094 \\
\hline Pseudo $R^{2}$ & 0.185 & 0.290 & 0.0616 & 0.194 \\
\hline \multicolumn{5}{|l|}{ Standard errors in parentheses } \\
\hline \multicolumn{5}{|l|}{${ }^{*} p<0.05,{ }^{* *} p<0.01,{ }^{* * *} p<0.001$} \\
\hline \multicolumn{5}{|c|}{$\begin{array}{l}\text { Models (2) and (4) exclude countries with no records of suicide attacks in the study } \\
\text { period }\end{array}$} \\
\hline
\end{tabular}




\subsubsection{Robustness checks}

I tested the same models with the share of depression as an alternative lence of depressive disorders (Global Burden of Disease Collaborative Network 2018). The share of depression only imperfectly correlated with the share of deaths from suicide in the study sample, $r(2971)=0.10, p=.000$. Hence the share of depression was not redundant with the share of deaths from suicide. of the share of deaths from suicide. Estimates converge with previous results. Results from model (1) and (2) indicated that the share of depression was positively and significantly related to the number of suicide attacks. In contrast, results from models (3) and (4) indicated that the share of depression was not significantly related to the number of non-suicide attacks.

Evidence indicates that 9/11 was a turning point in historical trends of terrorism (Smith \& Zeigler, 2017, Atran, 2006). I tested whether the effect of the share of deaths from suicide was found before and after 2001. Table A.8 presents estimates from the main models based on split samples. Results from model (1) to the number of suicide attacks both before and after 2001. Results from model (3) and (4) confirmed that the share of deaths from suicide was not significantly related to the number of non-suicide attacks both before and after 2001 .

\subsubsection{Control variables}

530

Although statistical significance was not achieved in all models, coefficients of the control variables were in the expected direction when significant. Overall, results from Table 3 , A.7 and A.8 suggested that the incidences of suicide and non-suicide attacks were higher in populated, rich, democratic countries with young institutions, high level of discrimination and which experienced civil war.

Note that the conclusion were unchanged when including these countries in model (4). Results can be sent by the author upon request. 
Besides, the share of Muslim population was positively related to both the number of suicide and non-suicide attacks. Finally, in contradiction with the view that suicide attacks are specifically used against foreign occupation (Pape 2006), results indicated that occupied countries experienced significantly more non-suicide attacks but did not experienced more suicide attacks.

\subsection{Discussion}

Study 2 analyzed the cross-national associations between the share of deaths from suicide and the number of suicide and non-suicide terrorist attacks. I found that countries with higher share of deaths form suicide experienced significantly more suicide terrorist attacks but a similar number of non-suicide attacks. These results support the hypothesis that suicide terrorism is related to common suicidal tendencies. The results revealed that other factors had generally similar effects on suicide and non-suicide terrorism. This supports the view that suicide terrorism follows a similar pattern than non-suicide terrorism, but that the difference between suicide and non-suicide terrorism reflects differences in suicidal tendencies.

Study 2 has several limitations. The number of terrorist attacks in a country is not a direct measure of the number of terrorists from this country. Unfortunately, there is no systematic data on the number of terrorists worldwide. It is yet reasonable to assume that the number of terrorist attacks depends on

the number of terrorists, and previous studies usually relied on the number of attacks to test hypotheses about terrorist mobilization (Krueger, 2017, Choi \& Piazza, 2016, 2017, Piazza, 2017, Ghatak et al., 2019; Freytag et al., 2011). Relatedly, the attacks analyzed in Study 2 mix both attacks perpetrated by national and foreign citizens. The suicidal hypothesis predicts that countries with higher prevalence of suicide tendencies experience more suicide attacks perpetrated by national citizens, but no more attacks perpetrated by foreign citizens, who come from countries with a different prevalence of suicidal tendencies. Unfortunately, the GTD does not identify the perpetrators' nationality. This issue is not highly problematic since the inclusion of attacks perpetrated by foreign 
reason to expect that foreign terrorists attack more countries with higher shares of deaths from suicides. Besides, studies based on different estimation methods suggest that around $75 \%$ to $85 \%$ of terrorist attacks recorded in the GTD are domestic (Kis-Katos et al., 2011; Enders et al., 2011, LaFree et al., 2014) 21

Another concerns is that estimates of the share of deaths from suicide could be unequally reliable across countries. Even though the GBD addressed crossnational variation in data quality through a range of correction (see Naghavi, 2019), one cannot exclude that suicide reporting practices differ across countries in correlation with reporting biases in the counting of terrorist attacks see no reason why suicide attacks in particular, but not non-suicide attacks, would be more systematically reported in countries that more systematically report deaths from suicide. Besides, results revealed that the effect of the share of deaths from suicide was still significant when including country fixed effects. This indicates that, putting aside the mean variations between countries, the share of deaths from suicide predicted longitudinal variations across countries in the number of suicide attacks. Finally, the share of depression offered an alternative measure of suicidal tendencies.

Overall, one cannot conclude from the results from Study 2 alone that suicide terrorists are suicidal. Such macro associations may always reflect some

\footnotetext{
${ }^{21}$ Some studies on domestic terrorism rely on data from Enders et al. (2011), who devised a method to classify GTD attacks as domestic and transnational. However, this classification method does not distinguish attacks according to the nationality of perpetrators (see LaFree et al. 2014 146-172, for a discussion). For instance, data from Enders et al. (2011) identified the 9/11 attacks as domestic. For that reason, I preferred to focus in the main analyses on the original GTD. However, I conducted the present analyses based on Enders et al. (2011) data, with update for recent years (Gaibulloev \& Sandler 2019). The results were unchanged. Results can be sent by the author upon request.

${ }^{22}$ For instance, it is possible that both deaths from suicide and terrorist attacks were systematically more reported in developed countries.
} 
ecological fallacy ${ }^{23}$ But given existing micro evidence from Study 1 and previpus studies on different geographical locations (Merari et al., 2009, Speckhard \& Ahkmedova, 2006, Lankford, 2013b), it is likely that this macro association reflects the fact that suicide terrorists are suicidal.

\section{Conclusion}

The hypothesis that suicide terrorists are suicidal has stimulated passionate opposition (Sela \& Shackelford, 2014, Atran, 2014, McCauley, 2014). Among its detractors, Atran (2014) argued that the suicidal hypothesis is a symptom of fundamental attribution error, i.e. the common human tendency to attribute others' behavior to psychological causes and to attribute one's behavior to external causes. Scholars who disregard the suicidal hypothesis may be subject to another common human tendency: base rate fallacy, i.e. focusing on specific cases and ignoring base rates (Kahneman \& Tversky, 1972). Around $1.6 \%$ of the US population dies from suicide (Naghavi, 2019). Among US domestic terrorists, the exact same proportion committed suicide in perpetrating violence. Hence, suicide terrorism may be no more than the statistical conjunction of suicide and terrorism.

Detractors of the suicidal hypothesis overlook the base rate of suicides. In doing so, they exclude that suicidal individuals may fight for a political cause. In fact, most individuals who will eventually commit suicide display normal social and clinical characteristics (Large et al., 2017). Suicidal individuals, as all humans, may have altruistic motives and believe in a political cause. Then, is there a more meaningful way to commit suicide than through advancing one's political cause? Since 1993, around 200 Palestinians died in perpetrating suicide

\footnotetext{
${ }^{23}$ For instance, individuals may be more inclined to fight to change the political system in countries with higher share of deaths from suicide, even if they are not suicidal themselves. Yet, in this case, I see no reasons why the share of deaths from suicide would only explain suicide terrorism and not non-suicide terrorism.
} 
Jewish Virtual Library, 2020). Over the same period, it can be estimated that 4,000 Palestinians died from common suicides ${ }^{24}$ Thus, if $5 \%$ of Palestinians who were to commit suicide anyway did it through suicide bombings against Israeli occupation, this would account for Palestinians suicide bombings over this period. Is this proportion unrealistic, given that a majority of the Palestinian population supports suicide attacks to fight Israeli occupation (Sharvit et al. 2015, Kohut \& Bell, 2013)?

This paper offers new micro and macro evidence supportive of the hypothesis that suicide terrorists are suicidal (Lankford, 2013a|b, Merari et al., 2009). These results are in contradiction with the foremost explanation of suicide terrorism as driven by altruistic devotion to the group (Atran, 2016, Pape, 2006 Ginges \& Atran, 2009; Swann et al., 2012; Sheikh et al., 2016; Whitehouse 2018 Ginges et al., 2009, Atran \& Sheikh, 2015). The present results do not indicate that suicide terrorists are not altruistic at all. Suicide terrorists are not suicidal individuals who randomly perpetrate violence. A simple look at the geographical and historical concentration of suicide attacks shows that suicidal tendencies do not randomly translate into suicide terrorism. Results from Study 2 confirm that suicide attacks are related to a range of contextual causes, that are essentially similar to those of terrorist attacks in general (Ghatak et al. ${ }_{630}$ 2019, Piazza, 2017, Choi \& Piazza, 2016, Krueger, 2017, Freytag et al. 2011 Kis-Katos et al., 2011). Hence, the present results do not contradict the view that altruism, as well as other factors, play a role in suicide terrorism. However, the results suggest that the difference between suicide and non-suicide terrorists may be simply explained by variations in suicidal tendencies.

Besides being empirically grounded, the suicidal hypothesis is parsimonious

\footnotetext{
${ }^{24}$ This estimation is based on applicating the GBD estimated yearly suicide rate of West Bank and Gaza to its population since 1993 to 2019 - with simple application of the 2016 suicide rate for the 2017-2019 period. With a mean estimated suicide rate of 4.5 per 100,000 inhabitants, West Bank and Gaza range among countries with the lowest suicide rates in the world.
} 
(Quine, 1964). Put simply, suicide terrorism is the conjunction of suicide and terrorism. Both phenomena are well documented and relatively under control for standard theories of human behavior. In contrast, the altruistic hypothesis encompasses a deep reconsideration of existing conceptions of humans, as basically interested in their preservation and not willing to sacrifice for non-kin relatives. It is not to say that existing conceptions should never be reconsidered. But such reconsideration should only be made in case of well-documented contradictory evidence. Evidence about suicide terrorism seems neither welldocumented nor contradictory enough to justify such reconsideration. In sum, suicide terrorism may well be a case of over-theorization based on fragmentary data.

\section{References}

Adams, D. M., \& Overholser, J. C. (1992). Suicidal behavior and history of substance abuse. The American journal of drug and alcohol abuse, 18, 343354.

Angelakis, I., Gillespie, E. L., \& Panagioti, M. (2019). Childhood maltreatment and adult suicidality: A comprehensive systematic review with meta-analysis. Psychological medicine, 49, 1057-1078.

Appleby, L., Cooper, J., Amos, T., \& Faragher, B. (1999). Psychological autopsy study of suicides by people aged under 35. The British Journal of Psychiatry, $175,168-174$.

Atran, S. (2003). Genesis of suicide terrorism. Science, 299, 1534-1539.

Atran, S. (2004). Mishandling suicide terrorism. The Washington Quarterly, 27, 65-90.

Atran, S. (2006). The moral logic and growth of suicide terrorism. Washington Quarterly, 29, 127-147. 
Atran, S. (2014). Martyrdom's would-be myth buster. Behavioral and Brain Sciences, 37, 362-363.

Atran, S. (2016). The Devoted Actor: Unconditional Commitment and Intractable Conflict across Cultures. Current Anthropology, 57, S192-S203. doi:10.1086/685495.

Atran, S., \& Sheikh, H. (2015). Dangerous terrorists as devoted actors. In Evolutionary Perspectives on Social Psychology (pp. 401-416). Springer.

Bhui, K., Warfa, N., \& Jones, E. (2014). Is violent radicalisation associated with poverty, migration, poor self-reported health and common mental disorders? PloS one, 9 .

Bowles, S. (2009). Did Warfare Among Ancestral Hunter-Gatherers Affect the 口 Evolution of Human Social Behaviors? Science, 324, 1293-1298. doi 10. 1126/science.1168112.

Brown, R. M., Brown, S. L., Johnson, A., Olsen, B., Melver, K., \& Sullivan, M. (2009). Empirical support for an evolutionary model of self-destructive motivation. Suicide and Life-Threatening Behavior, 39, 1-12.

Brown, R. M., Dahlen, E., Mills, C., Rick, J., \& Biblarz, A. (1999). Evaluation of an evolutionary model of self-preservation and self-destruction. Suicide and Life-Threatening Behavior, 29, 58-71.

Bruffaerts, R., Demyttenaere, K., Borges, G., Haro, J. M., Chiu, W. T., Hwang, I., Karam, E. G., Kessler, R. C., Sampson, N., \& Alonso, J. (2010). Childhood adversities as risk factors for onset and persistence of suicidal behaviour. The British journal of psychiatry, 197, 20-27.

Brym, R. J., \& Araj, B. (2012a). Are suicide bombers suicidal? Studies in Conflict \& Terrorism, 35, 432-443.

Brym, R. J., \& Araj, B. (2012b). Suicidality and suicide bombing revisited: A rejoinder to Merari. Studies in Conflict $\& 3$ Terrorism, 35, 733-739. 
Calati, R., Ferrari, C., Brittner, M., Oasi, O., Olié, E., Carvalho, A. F., \& Courtet, P. (2019). Suicidal thoughts and behaviors and social isolation: A narrative review of the literature. Journal of affective disorders, 245, 653-667.

Capellan, J. A. (2015). Lone wolf terrorist or deranged shooter? A study of ideological active shooter events in the United States, 1970-2014. Studies in Conflict $\mathscr{E}$ Terrorism, 38, 395-413.

Cavanagh, J. T., Carson, A. J., Sharpe, M., \& Lawrie, S. M. (2003). Psychological autopsy studies of suicide: A systematic review. Psychological medicine, 33, 395-405.

Center for Systemic Peace (2018a). Major Episodes of Political Violence (MEPV) and Conflict Regions, 1946-2016. http://www.systemicpeace.org/inscrdata.html.

Center for Systemic Peace (2018b). Polity IV Project - Political Regime Characteristics and Transitions, 1800-2016. http://www.systemicpeace.org/inscrdata.html.

Cherpitel, C. J., Borges, G. L., \& Wilcox, H. C. (2004). Acute alcohol use and suicidal behavior: A review of the literature. Alcoholism: clinical and experimental research, $28,18 \mathrm{~S}-28 \mathrm{~S}$.

Choi, J.-K., \& Bowles, S. (2007). The coevolution of parochial altruism and war. science, $318,636-640$.

Choi, S.-W., \& Piazza, J. A. (2016). Ethnic groups, political exclusion and domestic terrorism. Defence and Peace Economics, 27, 37-63.

Choi, S.-W., \& Piazza, J. A. (2017). Foreign military interventions and suicide attacks. Journal of Conflict Resolution, 61, 271-297.

Corner, E., \& Gill, P. (2015). A false dichotomy? Mental illness and lone-actor terrorism. Law and Human Behavior, 39, 23. 
Corner, E., \& Gill, P. (2017). Is there a nexus between terrorist involvement and mental health in the age of the Islamic State? The CTC Sentinel, 10, $1-10$.

Corner, E., Gill, P., \& Mason, O. (2016). Mental health disorders and the terrorist: A research note probing selection effects and disorder prevalence. Studies in Conflict \&3 Terrorism, 39, 560-568.

Dawkins, R. (2016). The Selfish Gene. Oxford university press.

de Catanzaro, D. (1995). Reproductive status, family interactions, and suicidal ideation: Surveys of the general public and high-risk groups. Ethology and Sociobiology, 16, 385-394.

Dube, S. R., Anda, R. F., Felitti, V. J., Chapman, D. P., Williamson, D. F., \& Giles, W. H. (2001). Childhood abuse, household dysfunction, and the risk of attempted suicide throughout the life span: Findings from the Adverse Childhood Experiences Study. Jama, 286, 3089-3096.

Enders, W., Sandler, T., \& Gaibulloev, K. (2011). Domestic versus transnational terrorism: Data, decomposition, and dynamics. Journal of Peace Research, 48, 319-337.

Franklin, J. C., Ribeiro, J. D., Fox, K. R., Bentley, K. H., Kleiman, E. M., Huang, X., Musacchio, K. M., Jaroszewski, A. C., Chang, B. P., \& Nock, M. K. (2017). Risk factors for suicidal thoughts and behaviors: A metaanalysis of 50 years of research. Psychological bulletin, 143, 187.

Freilich, J. D., Chermak, S. M., Belli, R., Gruenewald, J., \& Parkin, W. S. (2014). Introducing the United States extremis crime database (ECDB). Terrorism and Political Violence, 26, 372-384.

Freilich, J. D., Parkin, W. S., Gruenewald, J., \& Chermak, S. M. (2019). Comparing extremist perpetrators of suicide and non-suicide attacks in the United States. Terrorism and political violence, 31, 943-965. 
Freytag, A., Krüger, J. J., Meierrieks, D., \& Schneider, F. (2011). The origins of terrorism: Cross-country estimates of socio-economic determinants of terrorism. European Journal of Political Economy, 27, S5-S16.

Gaibulloev, K., \& Sandler, T. (2019). What we have learned about terrorism since 9/11. Journal of Economic Literature, 57, 275-328.

García, J., \& van den Bergh, J. C. J. M. (2011). Evolution of parochial altruism

口 by multilevel selection. Evolution and Human Behavior, 32, 277-287. doi 10 . 1016/j.evolhumbehav.2010.07.007.

Ghatak, S., Gold, A., \& Prins, B. C. (2019). Domestic terrorism in democratic states: Understanding and addressing minority grievances. Journal of conflict resolution, 63, 439-467.

Gill, P., Horgan, J., \& Deckert, P. (2014). Bombing alone: Tracing the motivations and antecedent behaviors of lone-actor terrorists. Journal of forensic sciences, 59, 425-435.

Ginges, J., \& Atran, S. (2009). What motivates participation in violent political action. Annals of the New York Academy of Sciences, 1167, 115-123.

Ginges, J., Hansen, I., \& Norenzayan, A. (2009). Religion and Support for Sui口 cide Attacks. Psychological Science, 20, 224-230. doi 10.1111/j.1467-9280. $2009.02270 . x$

Global Burden of Disease Collaborative Network (2018). Global Burden of Disease Study 2017 (GBD 2017) Results. http://ghdx.healthdata.org/gbdresults-tool.

Gruenewald, J., Chermak, S., \& Freilich, J. D. (2013). Distinguishing "loner" 765 attacks from other domestic extremist violence: A comparison of far-right homicide incident and offender characteristics. Criminology \& Public Policy, 12, 65-91. 
Hamermesh, D. S., \& Soss, N. M. (1974). An Economic Theory of Suicide. Journal of Political Economy, 82, 83-98. doi:10.1086/260171.

Houston, K., Hawton, K., \& Shepperd, R. (2001). Suicide in young people aged 15-24: A psychological autopsy study. Journal of affective disorders, 63, $159-170$.

Jewish Virtual Library (2020). Comprehensive Listing of Terrorism Victims in Israel. https://www.jewishvirtuallibrary.org/comprehensive-listingof-terrorism-victims-in-israel.

Johnston, W. R. (2018). Chronology of Terrorist Attacks in Israel. http://www.johnstonsarchive.net/terrorism/terrisrael.html.

Kahneman, D., \& Tversky, A. (1972). Subjective probability: A judgn ment of representativeness. Cognitive Psychology, 3, 430-454. doi 10.1016/ $780 \quad 0010-0285(72) 90016-3$

Kessler, R. C., Borges, G., \& Walters, E. E. (1999). Prevalence of and risk factors for lifetime suicide attempts in the National Comorbidity Survey. Archives of general psychiatry, 56, 617-626.

Kis-Katos, K., Liebert, H., \& Schulze, G. G. (2011). On the origin of domestic and international terrorism. European Journal of Political Economy, 27, S17-S36.

Kohut, A., \& Bell, J. (2013). Muslim Publics Share Concerns about Extremist Groups. Pew Research Center Washington, DC.

Krueger, A. B. (2017). What Makes a Terrorist.. PRINCETON UNIVERSITY PRES.

LaFree, G., Dugan, L., \& Miller, E. (2014). Putting Terrorism in Context: Lessons from the Global Terrorism Database. Routledge. 
LaFree, G., Jensen, M. A., James, P. A., \& Safer-Lichtenstein, A. (2018). Correlates of violent political extremism in the United States. Criminology, 56,

Langman, P. (2009). Rampage school shooters: A typology. Aggression and Violent Behavior, 14, 79-86. doi:10.1016/j.avb.2008.10.003.

Langman, P. (2013). Thirty-five rampage school shooters: Trends, patterns, and typology. In School Shootings: International Research, Case Studies, and Concepts for Prevention (pp. 131-156). New York, NY, US: Springer Science + Business Media. doi 10.1007/978-1-4614-5526-4_6.

Lankford, A. (2013a). A comparative analysis of suicide terrorists and rampage, workplace, and school shooters in the United States from 1990 to 2010. Homicide studies, 17, 255-274.

Lankford, A. (2013b). The Myth of Martyrdom: What Really Drives Suicide Bombers, Rampage Shooters, and Other Self-Destructive Killers. St. Martin's Press.

Lankford, A. (2014). Précis of the myth of martyrdom: What really drives suicide bombers, rampage shooters, and other self-destructive killers. The Behavioral and Brain Sciences, 37, 351-362. doi:10.1017/S0140525X13001581

Lankford, A. (2018). A psychological re-examination of mental health problems among the 9/11 terrorists. Studies in Conflict 83 Terrorism, 41, 875-898.

Large, M. M., Ryan, C. J., Carter, G., \& Kapur, N. (2017). Can we usefully stratify patients according to suicide risk? $B m j, 359, \mathrm{j} 4627$.

815

Liu, K.-y. (2009). Suicide rates in the world: 1950-2004. Suicide and LifeThreatening Behavior, 39, 204-213.

Maoz, Z., \& Henderson, E. A. (2013). The world religion dataset, 1945-2010: Logic, estimates, and trends. International Interactions, 39, 265-291.

Maynard Smith, J. (1976). Group Selection. Stony Brook Foundation, Inc. 
McCauley, C. (2014). How many suicide terrorists are suicidal? Behavioral and brain sciences, 37, 373-374.

Merari, A. (1990). The readiness to kill and die: Suicidal terrorism in the Middle East. Origins of terrorism: Psychologies, ideologies, theologies, states of mind, 9, 192-207.

Merari, A. (2010). Driven to Death: Psychological and Social Aspects of Suicide Terrorism. Oxford University Press.

Merari, A., Diamant, I., Bibi, A., Broshi, Y., \& Zakin, G. (2009). Personality characteristics of "self martyrs" / "suicide bombers" and organizers of suicide attacks. Terrorism and Political Violence, 22, 87-101.

Moghadam, A. (2006). Suicide terrorism, occupation, and the globalization of martyrdom: A critique of Dying to Win. Studies in Conflict 85 Terrorism, 29, 707-729.

Moghadam, A. (2009). Motives for Martyrdom: Al-Qaida, Salafi Jihad, and the

a Spread of Suicide Attacks. International Security, 33, 46-78. doi 10.1162/ isec.2009.33.3.46.

Naghavi, M. (2019). Global, regional, and national burden of suicide mortality 1990 to 2016: Systematic analysis for the Global Burden of Disease Study 2016. BMJ, 364. doi:10.1136/bmj. 194

National Consortium for the Study of Terrorism and Responses to Terrorism (START) (2017). Global Terrorism Database. http://www.start.umd.edu/gtd/.

National Consortium for the Study of Terrorism and Responses to Terrorism (START) (2018). Profiles of Individual Radicalization in the United States (PIRUS). http://www.start.umd.edu/data-tools/profiles-individualradicalization-united-states-pirus. 
Nock, M. K., Borges, G., Bromet, E. J., Alonso, J., Angermeyer, M., Beautrais, A., Bruffaerts, R., Chiu, W. T., De Girolamo, G., \& Gluzman, S. (2008). Cross-national prevalence and risk factors for suicidal ideation, plans and attempts. The British Journal of Psychiatry, 192, 98-105.

Pape, R. A. (2006). Dying to Win: The Strategic Logic of Suicide Terrorism. Random House Incorporated.

Perry, S., \& Hasisi, B. (2015). Rational Choice Rewards and the Jihadist Sui口 cide Bomber. Terrorism and Political Violence, 27, 53-80. doi 10.1080/ 09546553.2014 .962991 .

Piazza, J. A. (2017). Repression and terrorism: A cross-national empirical analysis of types of repression and domestic terrorism. Terrorism and Political Violence, 29, 102-118.

Quine, W. V. O. (1964). On Simple Theories of a Complex World. In J. R. Gregg, \& F. T. C. Harris (Eds.), Form and Strategy in Science: Studies Dedicated to Joseph Henry Woodger on the Occasion of His Seventiq eth Birthday (pp. 47-50). Dordrecht: Springer Netherlands. doi 10.1007/ 978-94-010-3603-0_6.

Sabri, A., \& Schulze, G. G. (2020). Are suicide terrorists different from 'regular militants'? Public Choice, . doi:10.1007/s11127-020-00817-2.

865 Sela, Y., \& Shackelford, T. K. (2014). The myth of the myth of martyrdom. Behavioral and Brain Sciences, 37, 376-377.

Sharvit, K., Kruglanski, A. W., Wang, M., Sheveland, A., Ganor, B., \& Azani, E. (2015). Palestinian public opinion and terrorism: A two-way street? Journal of Policing, Intelligence and Counter Terrorism, 10, 71-87.

Sheehan, I. S. (2014). Are suicide terrorists suicidal? A critical assessment of the evidence. Innovations in clinical neuroscience, 11, 81. 
Sheikh, H., Gomez, A., \& Atran, S. (2016). Empirical Evidence for the Devoted Actor Model. Current Anthropology, 57, S204-S209. doi:10.1086/686221.

Smith, M., \& Zeigler, S. M. (2017). Terrorism before and after 9/11 - a more 875 \ dangerous world? Research \& Politics, 4, 2053168017739757. doi 10.1177/ 2053168017739757.

Speckhard, A., \& Ahkmedova, K. (2006). The Making of a Martyr: Chechen

口 Suicide Terrorism. Studies in Conflict 83 Terrorism, 29, 429-492. doi 10. $1080 / 10576100600698550$

Stein, D. J., Chiu, W. T., Hwang, I., Kessler, R. C., Sampson, N., Alonso, J., Borges, G., Bromet, E., Bruffaerts, R., \& De Girolamo, G. (2010). Crossnational analysis of the associations between traumatic events and suicidal behavior: Findings from the WHO World Mental Health Surveys. PloS one, 5.

885 Swann, W. B., Jetten, J., Gómez, A., Whitehouse, H., \& Bastian, B. (2012). When group membership gets personal: A theory of identity fusion. Psychological review, 119, 441.

Vishwasrao, S., Schneider, M., \& Chiang, E. P. (2019). The Effects of Military Occupation on Growth. Kyklos, 72, 183-207.

${ }_{890}$ Vogt, M., Bormann, N.-C., Rüegger, S., Cederman, L.-E., Hunziker, P., \& Girardin, L. (2015). Integrating Data on Ethnicity, Geography, and Conflict: The Ethnic Power Relations Data Set Family. Journal of Conflict Resolution, . doi $10.1177 / 0022002715591215$.

Wade, S. J., \& Reiter, D. (2007). Does democracy matter? Regime type and suicide terrorism. Journal of Conflict Resolution, 51, 329-348.

Whitehouse, H. (2018). Dying for the group: Towards a general theory of extreme self-sacrifice. Behavioral and Brain Sciences, 41. 
Whitehouse, H., Jong, J., Buhrmester, M. D., Gómez, A., Bastian, B., Kavanagh, C. M., Newson, M., Matthews, M., Lanman, J. A., \& McKay, R. (2017). The evolution of extreme cooperation via shared dysphoric experiences. Scientific Reports, 7, 44292.

\section{Appendix A. Additional tables}


Table A.4: Distribution of variables across non near-suicide and near-suicide terrorists and bivariate statistical tests

\begin{tabular}{|c|c|c|c|}
\hline & $\begin{array}{l}\text { Non near-suicide } \\
(N=1,150)\end{array}$ & $\begin{array}{l}\text { Near-suicide } \\
(N=26)\end{array}$ & p-value \\
\hline \multicolumn{4}{|l|}{ Suicide risk factors } \\
\hline Child abuse & $3 \%$ & $23 \%$ & .000 \\
\hline History of mental illness & $14 \%$ & $19 \%$ & .570 \\
\hline Relationship troubles & $25 \%$ & $40 \%$ & .232 \\
\hline Absent parent/s & $34 \%$ & $25 \%$ & .592 \\
\hline History of alcohol/drug abuse & $13 \%$ & $15 \%$ & .767 \\
\hline Trauma & $36 \%$ & $40 \%$ & .787 \\
\hline \multicolumn{4}{|l|}{ Other factors } \\
\hline Mean age (s.d.) & $33(13)$ & $33(12)$ & .973 \\
\hline Gender & $93 \%$ & $96 \%$ & 1.000 \\
\hline Minority status & $38 \%$ & $54 \%$ & .152 \\
\hline Immigrant & $13 \%$ & $15 \%$ & .764 \\
\hline Military experience & $16 \%$ & $12 \%$ & .784 \\
\hline Previous criminal activity & $45 \%$ & $56 \%$ & .313 \\
\hline Education & & & .355 \\
\hline Less than high school & $17 \%$ & $11 \%$ & \\
\hline High school diploma & $26 \%$ & $16 \%$ & \\
\hline More than high school & $57 \%$ & $74 \%$ & \\
\hline Social stratum & & & .907 \\
\hline Low & $8 \%$ & $0 \%$ & \\
\hline Medium & $63 \%$ & $55 \%$ & \\
\hline High & $29 \%$ & $45 \%$ & \\
\hline Ideology & & & .096 \\
\hline Far-left & $12 \%$ & $21 \%$ & \\
\hline Far-right & $55 \%$ & $33 \%$ & \\
\hline Islamist & $34 \%$ & $46 \%$ & \\
\hline Lone & $24 \%$ & $38 \%$ & .109 \\
\hline Mean share of valid values (s.d.) & $64(15)$ & $80(12)$ & .000 \\
\hline
\end{tabular}

Notes. Sample size varies across variables. P-values $<.05$ in bold. P-values are based on Fisher's exact test (two-tailed) for binary variables, chi2 test for education, social stratum and ideology, and t-test (two-tailed) for age and share of valid values. 
Table A.5: Odds ratios from logistic regression analyses of near-suicide terrorism (versus non near-suicide terrorism)

\begin{tabular}{|c|c|}
\hline & (1) \\
\hline \multirow[t]{2}{*}{ Child abuse } & $3.942^{* *}$ \\
\hline & $(2.042)$ \\
\hline \multirow[t]{2}{*}{ Share of valid values } & $1.069^{* * *}$ \\
\hline & $(0.0170)$ \\
\hline Observations & 1176 \\
\hline Pseudo $R^{2}$ & 0.136 \\
\hline
\end{tabular}

Standard errors in parentheses

${ }^{+} p<0.10,{ }^{*} p<0.05,{ }^{* *} p<0.01,{ }^{* * *} p<0.001$

Table A.6: Description of Study 2 variables

\begin{tabular}{|c|c|c|c|c|c|}
\hline Variable & Obs & Mean & Std. Dev. & Min & $\operatorname{Max}$ \\
\hline Number of suicide attacks & 2971 & .55 & 6.88 & 0 & 236 \\
\hline Number of non-suicide attacks & 2971 & 21.3 & 112 & 0 & 3133 \\
\hline Share of deaths from suicide $t-1$ & 2971 & 1.31 & .863 & .109 & 6.61 \\
\hline Share of Muslim $t-1$ & 2971 & .256 & .359 & 0 & 1 \\
\hline Log GDP per capita $t-1$ & 2971 & 7.75 & 1.66 & 4.17 & 11.5 \\
\hline $\log _{\text {Population }} t-1$ & 2971 & 16.4 & 1.37 & 13.3 & 21 \\
\hline Discriminated population ${ }_{t-1}$ & 2971 & .0374 & .104 & 0 & .84 \\
\hline Democracy $_{t-1}$ & 2971 & 3.44 & 6.35 & -10 & 10 \\
\hline Regime durability $t-1$ & 2971 & 25 & 32.1 & 0 & 204 \\
\hline Civil war $t-1$ & 2971 & .161 & .793 & 0 & 6 \\
\hline Foreign military occupation $t-1$ & 2971 & .0313 & .174 & 0 & 1 \\
\hline
\end{tabular}


Table A.7: Unstandardized coefficients from negative binomial analyses of the number of terrorist attacks (tests with the alternative measure of suicidal tendencies)

\begin{tabular}{|c|c|c|c|c|}
\hline \multirow{3}{*}{$\begin{array}{l}\text { Dependent variable } \\
\text { Share of depression } t-1\end{array}$} & (1) & $(2)$ & $(3)$ & $(4)$ \\
\hline & \multicolumn{2}{|c|}{ Suicide attacks } & \multicolumn{2}{|c|}{ Non-suicide attacks } \\
\hline & $0.547^{*}$ & $4.237^{* *}$ & -0.0646 & -0.235 \\
\hline & $(0.240)$ & $(1.415)$ & $(0.0640)$ & $(0.497)$ \\
\hline \multirow[t]{2}{*}{ Share of Muslim ${ }_{t-1}$} & $4.168^{* * *}$ & -14.82 & $0.558^{* * *}$ & -4.657 \\
\hline & $(0.421)$ & $(10.11)$ & $(0.137)$ & $(3.039)$ \\
\hline \multirow{2}{*}{ Log GDP per capita $t-1$} & -0.0262 & $1.564^{* * *}$ & 0.0358 & 0.200 \\
\hline & $(0.105)$ & $(0.427)$ & $(0.0371)$ & $(0.139)$ \\
\hline \multirow[t]{2}{*}{ Log Population $_{t-1}$} & $1.037^{* * *}$ & $8.663^{* * *}$ & $0.984^{* * *}$ & $2.820^{* * *}$ \\
\hline & $(0.106)$ & $(2.046)$ & $(0.0360)$ & $(0.559)$ \\
\hline \multirow[t]{2}{*}{ Discriminated population ${ }_{t-1}$} & $6.937^{* * *}$ & $6.945^{*}$ & $1.883^{* * *}$ & -1.522 \\
\hline & $(1.150)$ & $(2.923)$ & $(0.410)$ & $(0.878)$ \\
\hline \multirow[t]{2}{*}{ Democracy $_{t-1}$} & $0.166^{* * *}$ & 0.0549 & $0.0783^{* * *}$ & 0.0299 \\
\hline & $(0.0334)$ & $(0.0412)$ & $(0.0102)$ & $(0.0164)$ \\
\hline \multirow{2}{*}{ Regime durability $t-1$} & 0.00497 & -0.0279 & $-0.0106^{* * *}$ & $-0.0150^{* *}$ \\
\hline & $(0.00513)$ & $(0.0145)$ & $(0.00157)$ & $(0.00529)$ \\
\hline \multirow[t]{2}{*}{ Civil war $t-1$} & -0.0172 & 0.274 & $0.388^{* * *}$ & $0.327^{* * *}$ \\
\hline & $(0.140)$ & $(0.152)$ & $(0.0548)$ & $(0.0602)$ \\
\hline \multirow{2}{*}{ Foreign military occupation $t-1$} & 0.274 & 0.271 & $0.491^{*}$ & $1.148^{*}$ \\
\hline & $(0.603)$ & $(0.999)$ & $(0.234)$ & $(0.491)$ \\
\hline \multirow[t]{2}{*}{ Constant } & $-23.33^{* * *}$ & $-164.2^{* * *}$ & $-14.46^{* * *}$ & $-39.70^{* * *}$ \\
\hline & $(1.913)$ & $(35.86)$ & $(0.668)$ & $(9.673)$ \\
\hline \multirow[t]{2}{*}{ lnalpha } & $2.924^{* * *}$ & $0.508^{* * *}$ & $1.486^{* * *}$ & $-0.112^{*}$ \\
\hline & $(0.0959)$ & $(0.139)$ & $(0.0303)$ & $(0.0559)$ \\
\hline Country fixed effects & No & Yes & No & Yes \\
\hline Year fixed effects & No & Yes & No & Yes \\
\hline Observations & 2971 & 1094 & 2971 & 1094 \\
\hline Pseudo $R^{2}$ & 0.120 & 0.291 & 0.0616 & 0.194 \\
\hline
\end{tabular}

Standard errors in parentheses

${ }^{*} p<0.05,{ }^{* *} p<0.01,{ }^{* * *} p<0.001$

Models (2) and (4) exclude countries with no records of suicide attacks in the study period 
Table A.8: Unstandardized coefficients from negative binomial analyses of the number of terrorist attacks (tests with split samples)

\begin{tabular}{|c|c|c|c|c|}
\hline \multirow{4}{*}{$\begin{array}{l}\text { Dependent variable } \\
\text { Share of deaths from suicide } t-1\end{array}$} & (1) & $(2)$ & $(3)$ & $(4)$ \\
\hline & \multicolumn{2}{|c|}{ Suicide attacks } & \multicolumn{2}{|c|}{ Non-suicide attacks } \\
\hline & $1.291^{* * *}$ & $1.075^{* * *}$ & -0.0399 & 0.114 \\
\hline & $(0.179)$ & $(0.138)$ & $(0.0477)$ & $(0.0653)$ \\
\hline \multirow[t]{2}{*}{ Share of Muslim ${ }_{t-1}$} & $1.937^{* *}$ & $5.885^{* * *}$ & -0.348 & $1.211^{* * *}$ \\
\hline & $(0.663)$ & $(0.473)$ & $(0.179)$ & $(0.210)$ \\
\hline \multirow[t]{2}{*}{ Log GDP per capita $t-1$} & 0.207 & $0.334^{* *}$ & -0.0923 & $0.166^{* *}$ \\
\hline & $(0.194)$ & $(0.119)$ & $(0.0490)$ & $(0.0555)$ \\
\hline \multirow[t]{2}{*}{ Log Population $_{t-1}$} & $0.804^{* * *}$ & $1.178^{* * *}$ & $0.852^{* * *}$ & $1.134^{* * *}$ \\
\hline & $(0.181)$ & $(0.110)$ & $(0.0502)$ & $(0.0511)$ \\
\hline \multirow[t]{2}{*}{ Discriminated population $t-1_{t}$} & $8.703^{* * *}$ & $10.000^{* * *}$ & $1.679^{* * *}$ & $2.519^{* * *}$ \\
\hline & $(1.536)$ & $(1.256)$ & $(0.463)$ & $(0.760)$ \\
\hline \multirow[t]{2}{*}{ Democracy $_{t-1}$} & $0.107^{*}$ & $0.133^{* * *}$ & $0.0770^{* * *}$ & $0.0809^{* * *}$ \\
\hline & $(0.0485)$ & $(0.0331)$ & $(0.0119)$ & $(0.0160)$ \\
\hline \multirow[t]{2}{*}{ Regime durability $t-1$} & -0.0179 & -0.00828 & $-0.00469^{*}$ & $-0.0131^{* * *}$ \\
\hline & $(0.0114)$ & $(0.00466)$ & $(0.00215)$ & $(0.00250)$ \\
\hline \multirow[t]{2}{*}{ Civil war $t-1$} & $0.419^{*}$ & $0.483^{* *}$ & $0.391^{* * *}$ & $0.460^{* * *}$ \\
\hline & $(0.212)$ & $(0.169)$ & $(0.0561)$ & $(0.119)$ \\
\hline \multirow[t]{2}{*}{ Foreign military occupation $t-1$} & -18.97 & 0.464 & -0.108 & $0.746^{*}$ \\
\hline & $(26608.5)$ & $(0.676)$ & $(0.350)$ & $(0.337)$ \\
\hline \multirow[t]{2}{*}{ Constant } & $-22.07^{* * *}$ & $-28.88^{* * *}$ & $-11.18^{* * *}$ & $-18.84^{* * *}$ \\
\hline & $(4.216)$ & $(2.209)$ & $(0.861)$ & $(0.922)$ \\
\hline \multirow[t]{2}{*}{ lnalpha } & $2.025^{* * *}$ & $2.257^{* * *}$ & $1.025^{* * *}$ & $1.703^{* * *}$ \\
\hline & $(0.331)$ & $(0.106)$ & $(0.0462)$ & $(0.0431)$ \\
\hline Period & Before 2001 & After 2001 & Before 2001 & After 2001 \\
\hline Observations & 1105 & 1733 & 1105 & 1733 \\
\hline Pseudo $R^{2}$ & 0.224 & 0.189 & 0.0601 & 0.0733 \\
\hline
\end{tabular}

